\title{
Repeated Antigenic Challenge-Induced Airway Hyperresponsiveness and Airway Inflammation in Actively Sensitized Rats
}

\author{
Miwa Misawa and Yoshihiko Chiba \\ Department of Pharmacology, School of Pharmacy, Hoshi University, Shinagawa-ku, Tokyo 142, Japan \\ Received July 10, 1992 Accepted October 29, 1992
}

\begin{abstract}
Airway hyperresponsiveness (AHR) is a critical component in bronchial asthma, but the underlying mechanisms remain to be disclosed. Our present studies were performed to establish a new good experimental animal model of AHR. Male Wistar rats actively sensitized with DNP-Ascaris antigen (DNPAsc) were challenged by inhaling DNP-Asc 8 days after the first immunization (single antigenic challenge). Another sensitization group received 3 challenges every $48 \mathrm{hr}$ (repeated antigenic challenge). The airway responsiveness to inhalations of acetylcholine (ACh) and neurokinin A (NKA) were determined under anesthesia. The airway microvascular leakage was also determined with Evans blue (E.B.). At $24 \mathrm{hr}$ after the single antigen challenge, the airway responsiveness to ACh and NKA were slightly enhanced, and the E.B. exudation was increased in the main bronchus. In contrast, the airway responsiveness to $\mathrm{ACh}$ and NKA and the E.B. exudation in the main bronchus were much more markedly enhanced $24 \mathrm{hr}$ after the repeated antigenic challenge. The isolated main bronchial strip from the challenged rats had obtained AHR towards $\mathrm{ACh}$ and serotonin. These findings suggest that repeated antigenic challenge causes a distinct AHR, both in vivo and in vitro, and that the airway inflammation may be closely related to pathogenesis of AHR.
\end{abstract}

Keywords: Hyperresponsiveness (airway), Inflammation (airway), Asthma (allergic), Bronchoconstriction

Nonspecific airway hyperresponsiveness (AHR) is a common feature in individuals with allergic bronchial asthma $(1,2)$. In allergic asthma, inhalation of allergen causes not only an immediate and reversible bronchoconstriction but also AHR to stimuli such as histamine and acetylcholine (ACh). The importance of the increased responsiveness in the pathogenesis of asthma has been suggested by its correlation with the severity of this disease $(1,3)$. It is thus very important to understand the underlying mechanisms of AHR for the sake of asthma therapy.

To understand the mechanisms of AHR, various animal models have been developed. O'Byrne et al. reported that prostaglandin $F_{2 \alpha}(4)$, leukotriene $B_{4}(5)$ and ozone (6) induced AHR to ACh in normal dogs. However, it is unlikely that these dog models resemble human allergic asthma because these animals were not made allergic. A frequently used animal model is guinea pigs that have been sensitized with ovalbumin (OA) together with some adjuvant $(7,8)$. However, this species has been considered to be immunologically different from humans with regard to the mechanisms of allergic asthma involving antibody (9).

Because allergic bronchoconstriction in rats has certain features in common with human allergic asthma, rats show good potential as an allergic asthmatic animal model $(10,11)$. It has been demonstrated that the immunoglobulin E (IgE) antibody was easily generated when rats were sensitized with DNP-Ascaris antigen (12). The sensitized rats also exhibit early and late asthmatic responses to antigen inhalation (13). In the present study, to investigate the underlying mechanisms of AHR, we first tried to develop a new animal model of AHR by utilizing this species. The relationship between AHR and airway inflammation in our rat model was also examined.

\section{MATERIALS AND METHODS}

\section{Antigen challenge}

Specific-pathogen-free male Wistar rats weighing $230-314 \mathrm{~g}$ ( $6-8$ weeks of age), purchased from Charles River Japan, Inc. were housed under standard laboratory conditions with free access to food and water. Animals were sensitized with 2,4-dinitrophenylated Ascaris suum 
extract (DNP-Asc, $2 \mathrm{mg}$ protein, s.c.) together with killed Bordetella pertussis $\left(2 \times 10^{10}\right)$ as an adjuvant and were boosted by DNP-Asc ( $0.5 \mathrm{mg}$ protein, i.m.) 5 days later, according to the method of Tada and Okumura (12). Eight days after the first immunization, the rats were challenged by inhaling DNP-Asc $(6 \mathrm{mg}$ protein $/ \mathrm{ml}$, 5-6 ml) with an ultrasonic nebulizer (TUR-3000, Nihon Kohden, Tokyo) for 20 min under the unanesthetized condition in a plexiglass box $(300 \times 200 \mathrm{~mm}$, height: $150 \mathrm{~mm}$ ). These animals were designated as the single challenge group and used for experiments $24 \mathrm{hr}$ after the antigenic challenge. Another group of animals called the repeated challenge group received 3 times antigenic challenge every $48 \mathrm{hr}$ by the same challenge method as described above. They were used 12, 24, 48 or $72 \mathrm{hr}$ after the last antigenic challenge. Control rats received the same immunization, but inhaled saline instead of the DNP-Asc challenge dose.

\section{In vivo determination of airway responsiveness}

The determination of airway responsiveness to ACh or neurokinin A (NKA) was measured $24 \mathrm{hr}$ after the last antigenic challenge. Rats were anesthetized with urethane $(2 \mathrm{~g} / \mathrm{kg}$, i.p. $)$, placed in the supine position and ventilated artificially through a tracheal cannula at a frequency of 70 breaths/min. Respiratory volume was adjusted at the beginning of the experiment so that ventilation overflow (VO) would be $0.5 \mathrm{ml}$ in each rat. Spontaneous respiration was stopped by an injection of pancuronium bromide $(1 \mathrm{mg} / \mathrm{kg}$, i.v.). The bronchomotor tone was measured by the modified Konzett-Rössler method (14). The lung was inflated at a fixed volume of air under a constant pressure $\left(5 \mathrm{cmH}_{2} \mathrm{O}\right)$, and VO was continuously recorded with a combination of a pneumotachograph (TP-602T, Nihon Kohden) and an integrator (EI-601G, Nihon Kohden). Systemic blood pressure was monitored with a pressure transducer (DX-300, Nihon Kohden) from a cannula inserted into the left carotid artery, and heart rate was measured with a tachometer (AT-601G, Nihon Kohden) with the systemic blood pressure as the trigger. All the above parameters were recorded on a polygraph (RM-6000, Nihon Kohden).

The rats were subjected to cumulative inhalation of ACh $(0.001-0.03 \%)$ or NKA $(0.0001-0.01 \%)$, each for $3 \mathrm{~min}$, by aerosolizing the solution contained in a specially devised plastic cylindrical chamber (capacity: $25 \mathrm{ml}$ ) that was introduced in an ultrasonic nebulizer (TUR3200, Nihon Kohden). The ultrasonic nebulizer with the plastic chamber was placed into the respiratory circuit so that the aerosolized mist was inhaled into the airway each time of ventilation.

In some experiments (at 8 days after the first immunization in the single challenge group and at the third challenge in the repeated challenge group), the antigenic challenge was performed under anesthesia by inhaling DNP-Asc for $20 \mathrm{~min}$ through the tracheal cannula, and the DNP-Asc-induced immediate type of bronchoconstriction was compared between the two groups.

\section{In vitro determination of airway responsiveness}

Twenty-four hours after the last antigenic challenge, the rats were sacrificed by a blow to the head and exsanguinated. The trachea and bronchus were rapidly removed, cleaned of adhering connective tissues and cut open longitudinally along its ventral surface. About a 5-mm length of the tracheal strip was isolated $5 \mathrm{~mm}$ under the larynx (5-6 cartilages), and the left bronchial strip was also isolated (about 5-mm length, 8-9 cartilages). Each tissue strip was then suspended in a $10-\mathrm{ml}$ organ bath, at a resting tension of $1 \mathrm{~g}$. The isometrical contraction of each strip was measured with a force-displacement transducer (TB-612T, Nihon Kohden) and recorded on a polygraph (RM-85, Nihon Kohden). The organ bath contained modified Krebs-Henseleit solution with the following composition: $118 \mathrm{mM} \mathrm{NaCl}, 4.7 \mathrm{mM} \mathrm{KCl}, 2.5 \mathrm{mM} \mathrm{CaCl}$, $1.2 \mathrm{mM} \mathrm{MgSO}, 25.0 \mathrm{mM} \mathrm{NaHCO}_{3}, 1.2 \mathrm{mM} \mathrm{KH}_{2} \mathrm{PO}_{4}$ and $10.0 \mathrm{mM}$ glucose. The buffer solution was maintained at $37^{\circ} \mathrm{C}$ and oxygenated with $95 \% \mathrm{O}_{2}-5 \% \mathrm{CO}_{2}$. During an equilibration period in the organ bath, the tissues were washed three to four times at 15 to $20 \mathrm{~min}$ intervals and equilibrated slowly to a baseline tension of $1 \mathbf{g}$ for both strips. A further period of $15 \mathrm{~min}$ was required for tissue stabilization. The concentration-response curves for ACh and serotonin (5-HT) were constructed cumulatively, with a concentration range of $10^{-7}-10^{-4} \mathrm{M}$. A higher concentration of agonist was successively added after attainment of a plateau response to the previous concentration. Under these conditions, reproducible concentration-response curves were obtained on the same tissue strip.

In our in vitro experiments, NKA $\left(10^{-8}-10^{-6} \mathrm{M}\right)$ had no effect on most of the tracheal and main bronchial strips, so that we used 5-HT instead of NKA as a pharmacological stimulant in the in vitro experiments.

\section{Determination of airway microvascular leakage}

At twenty-four hour or other time points after the last antigenic challenge, the rats were anesthetized with urethane $(2 \mathrm{~g} / \mathrm{kg}$, i.p.). Airway vascular permeability was quantified by the extravasation of Evans blue dye (E.B.) using a modification of the method of Evans et al. (15), which correlates well with extravasation of radiolabeled albumin (16). E.B. $(30 \mathrm{mg} / \mathrm{ml}$ in saline, filtered with paper filter $), 30 \mathrm{mg} / \mathrm{kg}$, and heparin $(600 \mathrm{U} / \mathrm{kg})$ were administered by i.v.-injection. Twenty minutes later, the animals were exsanguinated from the abdominal aorta, 
and then the thorax was opened and a blunt-ended 13gauge needle was passed through the right ventricle into the pulmonary artery. The pulmonary veins were incised to allow the outflow of perfusate, and the airways and lungs were perfused with $20-30 \mathrm{ml}$ of $1 \%$ paraformaldehyde in citrate-buffered saline ( $\mathrm{pH} 3.5$ ) to remove intravascular dye and to fix the tissues. After then, the trachea, main bronchus and lungs were removed and their wet weights were measured.

E.B. was extracted by incubating tissues in $1 \mathrm{ml}$ (trachea and main bronchus) or $3 \mathrm{ml}$ (lungs) of $100 \%$ formamide at $60^{\circ} \mathrm{C}$ for $24 \mathrm{hr}$, and its concentration was determined by light absorbance at $620 \mathrm{~nm}$ (U-2000 spectrophotometer, Hitachi) and by interpolation on a standard curve of E.B. concentrations $(3.125-50 \mu \mathrm{g} / \mathrm{ml})$. E.B. content from each sample was expressed as nanograms per milligram wet weight of tissue.

\section{Passive cutaneous anaphylaxis (PCA)}

To measure PCA titer, the blood specimens were obtained from the heart at 8 and 12 days after the first immunization and at 12, 24, 48 and $72 \mathrm{hr}$ after the last antigenic challenge. The blood specimens were immediately ice-cooled for $10 \mathrm{~min}$ and then centrifuged $\left(3000 \mathrm{rpm}, 4^{\circ} \mathrm{C}\right.$ for $10 \mathrm{~min}$ ). The sera obtained were stored at $-35^{\circ} \mathrm{C}$ until used.

Serial dilutions $(4-512)$ of the serum obtained from individual bleedings were injected intradermally in $0.05 \mathrm{ml}$ quantities into the shaved backs of normal rats. After $48 \mathrm{hr}$, the rats were i.v.-injected with DNP-Asc ( $2 \mathrm{mg}$ protein $/ 200 \mathrm{~g}$ body weight) with $1 \%$ E.B. $(0.5 \mathrm{ml} / 200 \mathrm{~g}$ body weight) into the tail veins. After $30 \mathrm{~min}$, they were exsanguinated from the cervical aorta, and the skin was reflected for measurement of the extent of extravasation of the dye. When the diameter was $\geq 5 \mathrm{~mm}$, the dilution was determined to be the end point.

\section{Histological examination}

For histological examination, 5 to 7 rats of each group (control, single challenge and repeated challenge groups) were used. These animals were exsanguinated from the abdominal aorta, and the lower airway was removed after opening the thorax. Then the tissue was gently washed with normal saline and fixed in neutral formalin solution. The trachea, main bronchus and lung were cut into 3-5 $\mathrm{mm}$ chips, and each of the chips was embedded in paraffin by a standard technique. The paraffin sections were stained with hematoxylin and eosin.

\section{Drugs}

The following drugs were used: acetylcholine chloride (purchased from Daiichi Pharmaceutical Co., Ltd., Tokyo); NKA (from Peptide Institute, Inc., Osaka); pan- curonium bromide (from Sankyo Pharmaceutical Co., Ltd., Tokyo); serotonin (5-hydroxytryptamine hydrochloride) and urethane (ethyl carbamate) (from Sigma Chemical Co., Ltd., St. Louis, USA). Evans blue was obtained from Merck Co., Ltd. (New Jersey, USA). Heparin sodium was from Kodama Co., Ltd. (Tokyo).

For the in vivo studies, ACh, NKA and pancuronium bromide were freshly made just before use. Just before use in the in vitro studies, fresh solutions of ACh and serotonin were made in Krebs-Henseleit solution (composition described above). Urethane and Evans blue were dissolved in saline and stocked at room temperature. Heparin solution was diluted freshly in saline each day.

\section{Statistical analyses}

All the data except for the PCA titers are expressed as the mean with S.E. Statistical significance of difference was determined by Student's $t$-test for unpaired data or the Cochran-Cox test. The potency ratio of the in vivo bronchoconstrictor response to ACh or NKA was calculated by parallel line assay. The PCA titer of each group is expressed as the mean and its statistical significance was determined by the Wilcoxon rank-sum test.

\section{RESULTS}

Comparison of antigen induced-bronchoconstrictions between single and repeated challenge groups

Eight days after the first immunization, inhalation of aerosolized DNP-Asc ( $6 \mathrm{mg}$ protein $/ \mathrm{ml}, 20 \mathrm{~min}$ ) to sensitized rats under anesthesia (First challenge) induced an increase in ventilation overflow (VO as an index of bronchoconstriction) (Table 1). A similar, but slightly stronger, response was confirmed at the last antigenic challenge in the repeated challenge group (Last challenge). However, there was no significant difference between the groups in the maximal increase in VO $\left(\mathrm{VO}_{\max }\right)$ nor the time for reaching $\mathrm{VO}_{\max }\left(\mathrm{T}_{\max }\right)$ during inhalation of DNPAsc.

Table 1. The maximal increase in ventilation overflow $\left(\Delta \mathrm{VO}_{\max }\right)$ and the time for reaching $\mathrm{VO}_{\max }\left(\mathrm{T}_{\max }\right)$ during DNP-Asc $(6 \mathrm{mg}$ protein/ml) challenge for $20 \mathrm{~min}$ under anesthesia

\begin{tabular}{llll}
\hline & $\mathrm{n}$ & $\Delta \mathrm{VO}_{\max }(\mathrm{ml})$ & $\mathrm{T}_{\max }(\min )$ \\
\hline First challenge & 6 & $0.41 \pm 0.05$ & $15.1 \pm 1.8$ \\
Last challenge & 5 & $0.51 \pm 0.05^{\mathrm{ns}}$ & $13.8 \pm 1.6^{\mathrm{as}}$ \\
\hline
\end{tabular}

$\triangle \mathrm{VO}_{\max }$ and $\mathrm{T}_{\max }$ were expressed as the mean \pm S.E. First challenge: 8 days after the first immunization (matched for the antigenic challenge of the single challenge group). Last challenge: 12 days after the first immunization (matched for the last antigenic challenge of the repeated challenge group). ${ }^{\text {ns: }}$ no significant difference from the first challenge group. 


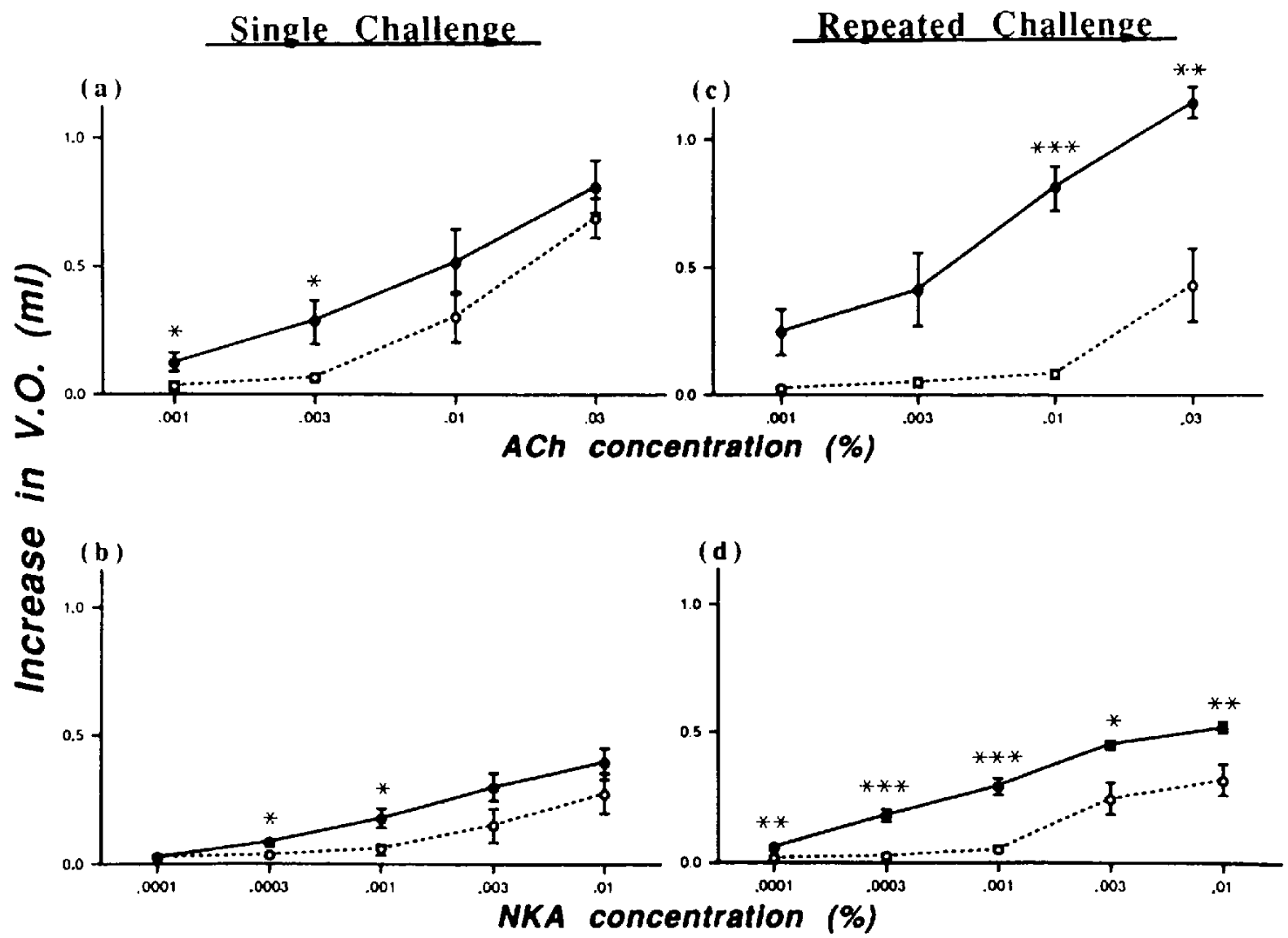

Fig. 1. The concentration-response curves of bronchomotor response to aerosolized acetylcholine (ACh: a and c) and neurokinin A (NKA: $b$ and d) after single ( $a$ and b) or repeated ( $c$ and d) challenge with DNP-Ascaris antigen (Asc) in anesthetized rats. Each point represents the mean with S.E. from 5 (saline control) and 6 (Asc) experiments in (a), from 6 (saline control) and 7 (Asc) experiments in (c), from 5 (control: $3 \times$ Sal) and $6(3 \times$ Asc) experiments in (b) and from 5 (control: $3 \times$ Sal) and 8 $(3 \times$ Asc) experiments in (d). V.O.: ventilation overflow as an index of bronchoconstriction (see Materials and Methods). ${ }^{*} \mathrm{P}<0.05,{ }^{* *} \mathrm{P}<0.01$ and ${ }^{* * *} \mathrm{P}<0.001$ vs. control group. $\cdots \bigcirc \cdots$; control, $-\mathrm{O}$ : Asc.

\section{Change in airway responsiveness after single antigen} challenge

Inhalation of four cumulative aerosols of ACh $(0.001$, $0.003,0.01$ and $0.03 \%$, each for $3 \mathrm{~min}$ ) to anesthetized control rats induced a concentration-related bronchoconstriction (Fig. 1a). When the animals were challenged only once with DNP-Asc, the concentration-response curve to ACh was shifted to the left 3.2-fold in terms of the concentration ratio, $24 \mathrm{hr}$ after the challenge. The airway responsiveness to $\mathrm{ACh}$ was significantly enhanced at concentrations of 0.001 and $0.003 \%(P<0.05)$. Similar results were obtained with NKA $(0.0001,0.0003,0.001$, 0.003 and $0.01 \%$, each for $3 \mathrm{~min}$ ) (Fig. 1b); the concentration-response curve was shifted to the left (sixfold) $24 \mathrm{hr}$ after the single antigenic challenge. The airway responsiveness to NKA was significantly enhanced at concentrations of 0.0003 and $0.001 \%(\mathrm{P}<0.05)$.
Change in airway responsiveness after repeated antigen challenge

The airway responsiveness to inhaled $\mathrm{ACh}$ was much more markedly increased $24 \mathrm{hr}$ after the repeated antigenic challenge.

Figure 1c shows the concentration-response curve for inhaling ACh $24 \mathrm{hr}$ after the last antigenic challenge. In the repeated challenge group, a dramatic leftward shift of the concentration-response curve (12.0 times; its $95 \%$ confidence interval: $6.1-63.9, \mathrm{P}<0.05$ ) was observed, as compared with the single challenge group. Similar results were obtained with comulative inhalation of NKA; the concentration-response curve was shifted to the left (12.4fold; its 95\% confidence interval: 9.0-19.5, $\mathrm{P}<0.05$ ) $24 \mathrm{hr}$ after the last antigenic challenge (Fig. 1d).

The AHR to ACh observed $24 \mathrm{hr}$ after the last antigenic challenge was completely blocked by atropine (1 $\mathrm{mg} / \mathrm{kg}$, i.v.). 


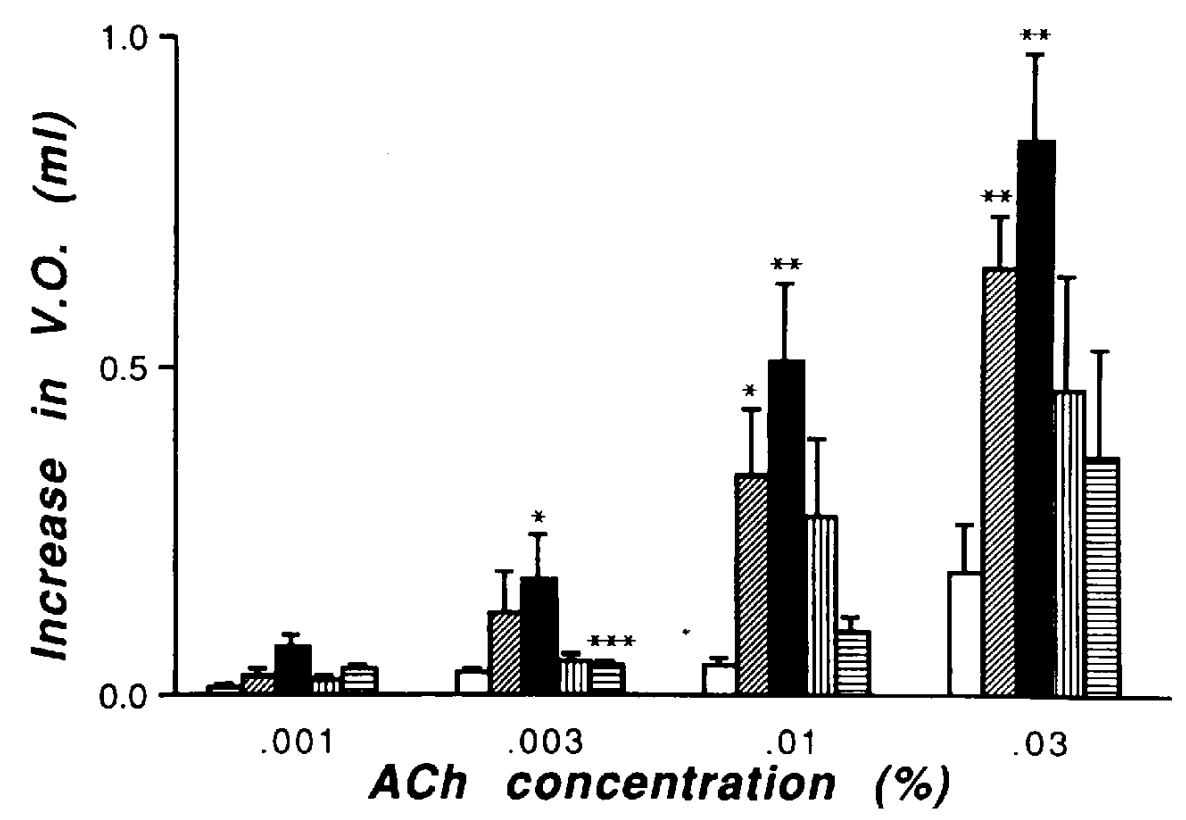

Fig. 2. The time course changes in response to acetylcholine (ACh) after the last DNP-Ascaris antigen (Asc) challenge in anesthetized rats. Each point represents the mean with S.E. from 5 (control $\square: 24 \mathrm{hr}$ after inhaling saline), 7 (四: $12 \mathrm{hr}$ after the

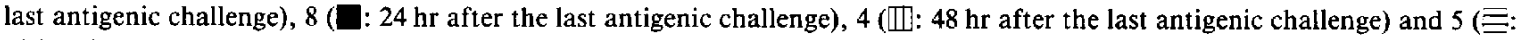
$72 \mathrm{hr}$ after the last antigenic challenge) experiments. V.O.: ventilation overflow as an index of bronchoconstriction. ${ }^{*} \mathrm{P}<0.05$, ${ }^{* *} \mathrm{P}<0.01$ and ${ }^{* * *} \mathrm{P}<0.001$ vs. control group.

Time course of $A H R$ to $A C h$ after repeated antigen challenge

Figure 2 shows the time course of airway responsiveness to ACh after the last DNP-Asc challenge in the repeated challenge group. The airway responsiveness to ACh was stronger in the following order, $24 \mathrm{hr}>12 \mathrm{hr}$ $>48 \mathrm{hr}>72 \mathrm{hr}$ after the last DNP-Asc challenge. The most severe airway hyperresponsiveness was thus shown at $24 \mathrm{hr}$ after the last antigenic challenge. At $72 \mathrm{hr}$ after the last antigenic challenge, however, the airway responsiveness almost recovered to the control level.

The antibody titer was measured by 48 -hr passive cutaneous anaphylaxis (PCA) at 8 and 12 days after the first immunization and at 12, 24, 48 and $72 \mathrm{hr}$ after the last antigenic challenge (Table 2). There was no significant difference in PCA titers among the groups, except that the titer at $72 \mathrm{hr}$ after the last challenge was significantly lower than that at $24 \mathrm{hr}(\mathrm{P}<0.05)$.

\section{Change in the in vitro airway tissue responsiveness after repeated antigen challenge}

ACh elicited a concentration-dependent contractile response of the rat tracheal and bronchial strips (Fig. 3, a and c). In the control (saline inhalation) group, the contractile response elicited by $10^{-4} \mathrm{M}$ ACh was $1.11 \pm 0.06 \mathrm{~g}$ $(\mathrm{n}=8)$ in the trachea and $0.38 \pm 0.05 \mathrm{~g}(\mathrm{n}=8)$ in the bronchus (Fig. 3, a and c). As compared with the control group, the contractile response of the bronchial strips was significantly enhanced $24 \mathrm{hr}$ after the last antigenic challenge in the repeated challenge group; the contractile response elicited by $10^{-4} \mathrm{M}$ ACh was $1.00 \pm 0.08 \mathrm{~g}(\mathrm{n}=6$, $P<0.001$ ). No change in responsiveness of the tracheal strips $(n=6)$ was, however, observed even after the antigenic challenge.

5-HT elicited relatively small contractile responses of

Table 2. The passive cutaneous anaphylaxis (PCA) titers at various time points

\begin{tabular}{rrcc}
\hline & n & Mean PCA titer & PCA range \\
\hline Day 8 & 5 & 21.2 & $2-64$ \\
Day 12 & 5 & 30.4 & $8-64$ \\
Challenge after & & & \\
$12 \mathrm{hr}$ & 5 & 22.8 & $2-64$ \\
$24 \mathrm{hr}$ & 14 & 40.0 & $8-256$ \\
$48 \mathrm{hr}$ & 5 & 32.4 & $2-128$ \\
$72 \mathrm{hr}$ & 7 & $12.3^{*}$ & $2-32$ \\
\hline
\end{tabular}

PCA titer was expressed as the mean of the end points determined as described in Materials and Methods. Day 8: the day just before the first antigenic challenge. Day 12: the day just before the last antigenic challenge. Challenge after 12, 24, 48 and $72 \mathrm{hr}: 12,24,48$ and $72 \mathrm{hr}$ after the last antigenic challenge. ${ }^{*} \mathrm{P}<0.05$ vs. challenge after the 24-hr group (Wilcoxon rank-sum test). 


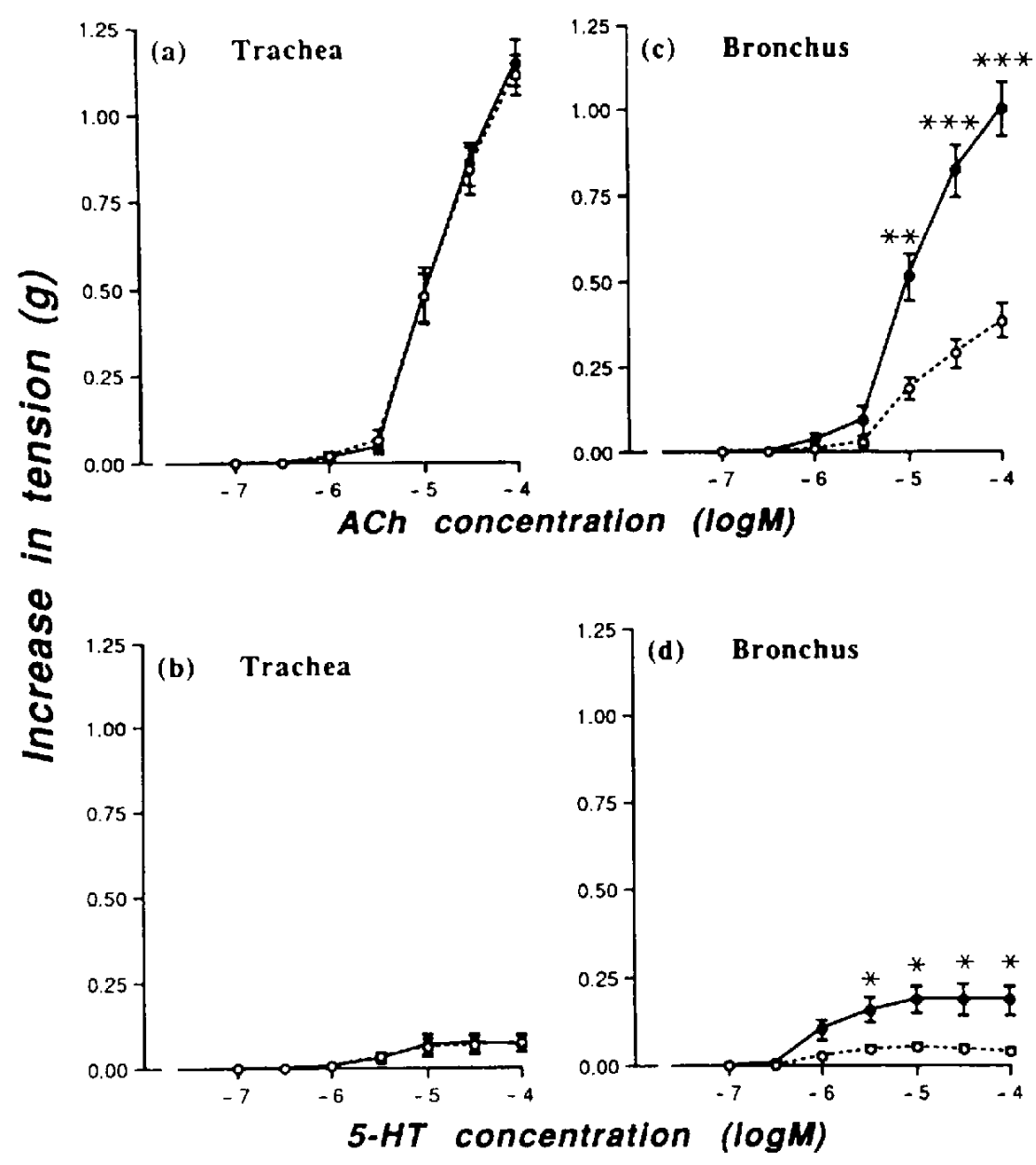

Fig. 3. The concentration-response curves of contractile responses of the isolated trachea ( $a$ and $b$ ) and bronchus (c and d) to acetylcholine (ACh: $a$ and $c$ ) and serotonin (5-HT: $b$ and d) after 3 times repeated challenge with DNP-Ascaris antigen (Asc) or saline (Sal) inhalation in sensitized rats. Each point represents the mean with S.E. from 8 (conrtol: $3 \times$ Sal) and $6(3 \times$ Asc) experiments in (a) and (c) and from 5 (control: $3 \times$ Sal $)$ and $5\left(3 \times\right.$ Asc) experiments in (b) and (d). ${ }^{*} \mathrm{P}<0.05,{ }^{* *} \mathrm{P}<0.01$ and ${ }^{* * *} \mathbf{P}<0.001$ vs. control group. $\cdots \bigcirc \cdots$ : control, $-\mathbf{O}$ : Asc.

the rat tracheal and bronchial strips (Fig. 3, b and d). In the control group, the maximal contractile response elicited by $10^{-4} \mathrm{M} 5$ - $\mathrm{HT}$ was $0.07 \pm 0.03 \mathrm{~g}(\mathrm{n}=5)$ in the tracheal strips and that elicited by $3 \times 10^{-5} \mathrm{M} 5$-HT in the bronchial strips was $0.05 \pm 0.01 \mathrm{~g}(\mathrm{n}=5$ ) (Fig. 3, b and $\mathrm{d}$ ). The contractile responses caused by 5 -HT were also significantly enhanced in the bronchial strips which were excised $24 \mathrm{hr}$ after the last antigenic challenge; the maximal contractile response elicited by $3 \times 10^{-5} \mathrm{M}$ 5-HT was $0.19 \pm 0.04 \mathrm{~g}(\mathrm{n}=5, \mathrm{P}<0.05)$.

\section{Change in microvascular leakage after antigen challenge}

Figure 4 shows E.B. extravasation in the tracheal, main bronchial and lung tissues at $24 \mathrm{hr}$ after the single challenge and at 12 or $24 \mathrm{hr}$ after the last challenge of the 3 times repeated challenge. E.B. extravasation in the trachea was significantly increased at $24 \mathrm{hr}$ after the repeated challenge ( $P<0.05$ vs. control). In the main bronchus, E.B. extravasation was significantly increased at $24 \mathrm{hr}$ after the single challenge ( $\mathrm{P}<0.01$ vs. control), but a more marked increase in E.B. extravasation was observed at 12 and $24 \mathrm{hr}$ after the repeated challenge $(\mathrm{P}<0.001$ and $\mathrm{P}<0.01$ vs. single challenge group, respectively). On the other hand, E.B. extravasation in the lungs was increased in none of the challenge groups.

The E.B. extravasations in the tracheal $(12.16 \pm 4.15$ $\mathrm{ng} / \mathrm{mg}$ tissue, $\mathrm{n}=5$ ), main bronchial $(11.65 \pm 2.00 \mathrm{ng} / \mathrm{mg}$ tissue, $n=5)$ and lung ( $3.62 \pm 0.24 \mathrm{ng} / \mathrm{mg}$ tissue, $n=5)$ tissues $48 \mathrm{hr}$ after the last antigenic challenge were not significantly different from the respective control value (data not shown). 


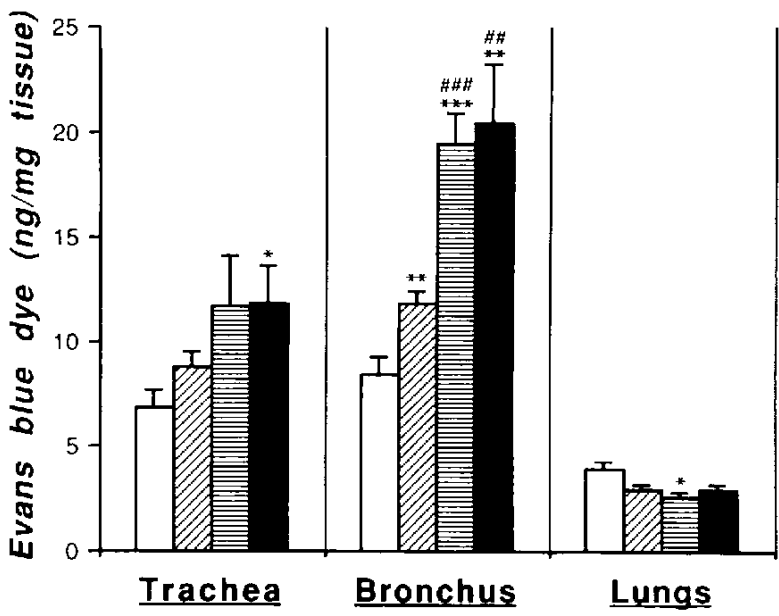

Fig. 4. The changes in amount of extravasated Evans blue dye (ng Evans blue dye/mg wet weight tissue) in the rat trachea (left panel), main bronchus (middle panel) and lungs (right panel). Each column represents the mean with S.E. from 8 (control $\square$ : $24 \mathrm{hr}$ after inhaling sline), 11 (四: $24 \mathrm{hr}$ after the single antigenic challenge), 5 ( $12 \mathrm{hr}$ after the last antigenic challenge) and 8 ( $\square: 24 \mathrm{hr}$ after the last antigenic challenge) experiments. ${ }^{*} \mathrm{P}<0.05,{ }^{* *} \mathrm{P}<0.01$ and ${ }^{* * *} \mathbf{P}<0.001$ vs. control group. ${ }^{\text {Hth }} \mathrm{P}<0.01$ and ${ }^{\# \# * t} \mathrm{P}<0.001$ vs. single challenge group.

\section{Histological analysis}

Some histological studies were performed on the various tissues. Figures 5 and 6 show the main bronchial tissues stained with hematoxylin and eosin from the control and repeatedly challenged rats, respectively. Twenty-four hours after the repeated challenge, mast cell and inflammatory cell (monocytes, lymphocytes, polynuclear cells, etc.) infiltration was markedly increased. The infiltration of these cells was more severe in the repeated challenge group (Fig. 6) than in the single challenge group (data not shown). In the repeated challenge group, the main bronchus was affected more severely than the trachea and lungs. Furthermore, epithelial cells were moderately changed (e.g., increased and hypertrophied goblet cells), especially in the main bronchus.

\section{DISCUSSION}

Our results demonstrated that repeated antigenic challenge caused a distinct AHR (enhanced airway responsiveness to inhaled ACh and NKA) and airway inflammation (increased airway microvascular leakage and histological change) in actively sensitized rats. The peak of AHR to ACh was shown at $24 \mathrm{hr}$ after the last antigenic challenge. At this time point, it was found that the AHR could be obtained even in the in vitro level, that is, in bronchial tissue. A severe airway inflammation was demonstrated at $12-24 \mathrm{hr}$ after the last antigenic challenge in the bronchus.

$\mathrm{ACh}$ and NKA were used to determine the in vivo airway responsiveness. ACh was frequently used for the test of AHR in clinical diagnosis. NKA, one of the putative neurotransmitters of the excitatory non-adrenergic, noncholinergic nervous system, is a potent bronchoconstrictor agent (17). In the present study, the AHR to ACh was completely blocked by atropine, indicating that there existed a muscarinic hyperreactivity. However, this is not a specific hyperreactive response because the airway responsiveness to NKA was also enhanced.

When rats were sensitized with DNP-Asc antigen according to the method of Tada and Okumura (12), the $48 \mathrm{hr}$ PCA titer (IgE antibodies are involved) is known to reach the maximal level at 8 days after the first immunization. Thus, at first, this time point was selected to carry out the antigenic challenge (to elicit the immediate asthmatic response) under unanesthesia. The objective symptoms observed were analogous to those of allergic bronchial asthma (e.g., abnormality of breaths) in all the animals used.

Presently, the airway responsiveness to ACh and NKA were significantly enhanced at $24 \mathrm{hr}$ after the single challenge, but the enhanced level was not so potent. Generally, with regard to allergic bronchial asthmatics, they are continually exposed to a certain antigen (e.g., house dust). Recently, with this view in mind, repeated antigenic challenge to sensitized animals has been attempted by some investigators $(18-20)$. On the other hand, Bellofiore and Martin (18) reported that the gradual desensitization to $O A$ antigen was elicited after 6 times repeated challenge in Brown-Norway rats. In our experiments, the antigenic challenge protocol of 3 times repeated challenge every $48 \mathrm{hr}$ successfully produced a marked increased responsiveness to $\mathrm{ACh}$ and NKA $24 \mathrm{hr}$ after the last challenge of the repeated challenge.

Twenty-four hours after the last antigenic challenge, the in vitro airway responsiveness to $\mathrm{ACh}$ and 5-HT were also enhanced in the main bronchus but not in the trachea. The airway microvascular leakage was more markedly increased in the bronchus than in the trachea. Furthermore, in our histological study, infiltration of inflammatory cells was much more severe in the bronchus than in the trachea. It has been thought that airway inflammation is induced by some chemical mediators such as prostaglandins, leukotrienes (LTs), thromboxane $\mathrm{A}_{2}$ $\left(\mathrm{TXA}_{2}\right)$, and platelet-activating factor (PAF) derived from the inflammatory cells (e.g., mast cells, neutrophils, eosinophils), which results in AHR $(21,22)$. Additionally, neuropeptides which are contained in the sensory nerve endings (23), may be also involved in the occurrence of airway inflammation. The difference in the present results between the tracheal and main bronchial regions is 


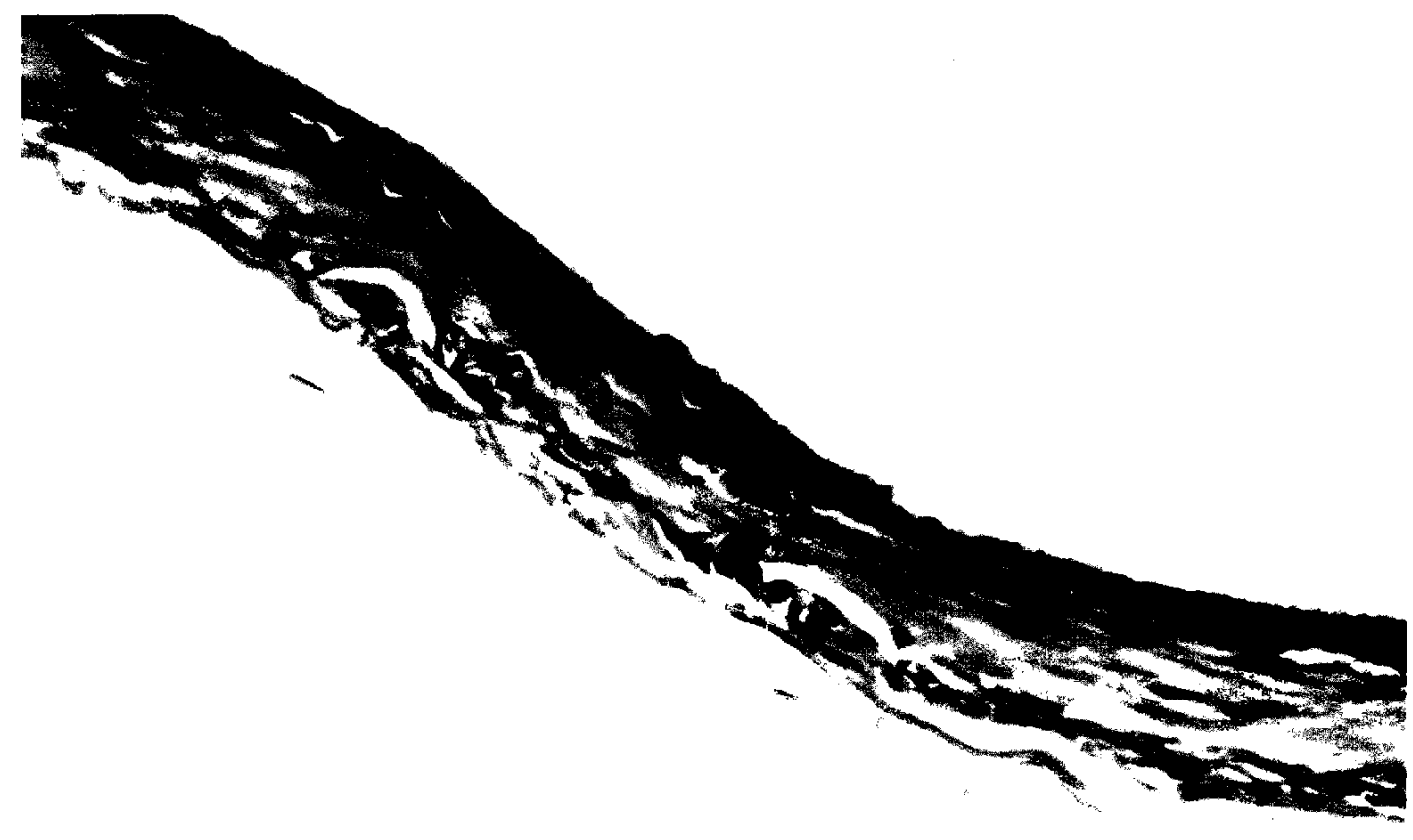

Fig. 5. A photograph showing the main bronchus from the control rat (without antigenic challenge) $(\times 400)$. Hematoxylin-eosin staining.

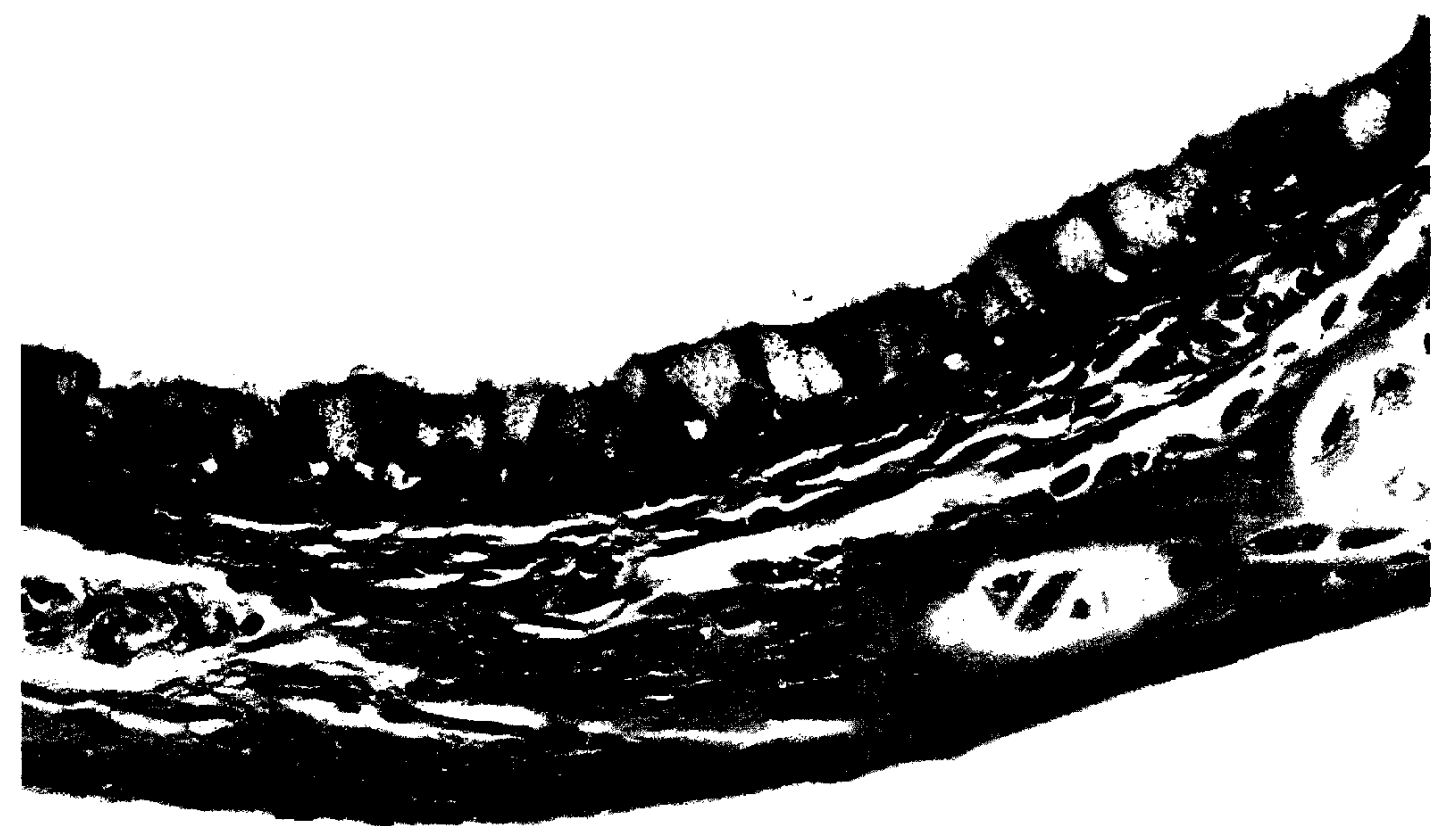

Fig. 6. A photograph showing the main bronchus from the repeated-antigen-challenged rat $(\times 400)$. Hematoxylin-eosin staining. 
not now explainable. It was, however, possible that because the distribution of these inflammatory cells might be more abundant in the main bronchus, the chemotaxis of these inflammatory cells might be caused more strongly in the main bronchus than in the trachea. Another possibility is that the neural control of the main bronchus might be essentially different from that of the trachea (e.g., the regional difference of responsiveness to $\mathrm{ACh}$, carbachol (24) and $\mathrm{LTC}_{4}(25)$ was reported in rats and excitatory nonadrenergic, noncholinergic innervation is much abundant in the bronchial region than in the tracheal region in guinea pigs (26)). Furthermore, it is possible that there may be a difference in physical adhesion of the antigen to the airway lumenal surface as compared to its adhesion in the bronchus. This regional difference in the airway inflammation was likely to reflect the regional difference in the AHR in the in vitro experiments also.

It has been reported that an antigenic challenge to sensitized guinea pigs (27) and rabbits (28) resulted in an airway smooth muscle hyperresponsiveness in vitro. These animals also obtained AHR in the in vivo level $(7,28)$. These findings therefore suggest that the increased airway smooth muscle responsiveness itself may be reflected in the in vivo AHR. Our result that the responsiveness to $\mathrm{ACh}$ and 5-HT were enhanced in the bronchial tissue in vitro supports this speculation. However, attempts to demonstrate hyperresponsiveness of isolated airway smooth muscle strips from asthmatics in vitro have so far produced varied results. There seems to be little or no increase in the sensitivity of airway strips from asthmatics (obtained post-mortem) $(29,30)$. In contrast, some studies, particularly those using surgical specimens, have described a substantial increase in muscle responsiveness $(31-33)$.

In our findings, a close relationship between the bronchial inflammation and the AHR was demostrated. That is, the peak of the airway inflammation was shown at 12-24 hr after the last antigenic challenge and the peak of the AHR was shown at $24 \mathrm{hr}$ after the last challenge. When dogs inhaled ozone, a close association was observed between the development of AHR and an acute inflammatory response in the airways, as measured by an influx of neutrophils into the epithelial and sub-epithelial layers of the airways (34) and bronchoalveolar fluid (35). Furthermore, in other animal preparations such as rabbits (36), guinea pigs (37) and even in humans (38), airway inflammation had also occurred at the same time as the development of AHR. Gibson et al. (39) reported that stable asthmatic individuals who were subjected to the provocation test with allergen inhalation demonstrated an increased histamine airway responsiveness at $24 \mathrm{hr}$ after the provocation, accompanied by airway inflammation. Their results are in good accordance with ours in terms of time course. In the present study, the airway inflammation (as evaluated by the E.B. exudation and histological examination) was induced in the main bronchus after the single antigenic challenge to sensitized rats, and a more severe inflammatory reaction was induced after the repeated antigenic challenge. It is likely that the antigenic challenge to sensitized rats caused an airway inflammation which was followed by AHR.

The present rat AHR model is considered to be useful for studying the underlying mechanisms of pathogenesis of AHR and for screening therapeutic drugs for AHR.

\section{REFERENCES}

1 Cockeroft, D.W., Killian, D.N., Mellon, J.J.A. and Hargreave, F.E.: Bronchial reactivity to inhaled histamine: a method and clinical survey. Clin. Allergy 7, 235-245 (1977)

2 Magnussen, H. and Nowak, D.: Roles of hyperresponsiveness and airway inflammation in bronchial asthma. Respiration $\mathbf{5 5}$, 65-74 (1989)

3 Hargreave, F.E., Ryan, G., Thomson, N.C., O'Byrne, P.M., Latimer, K. and Juniper, E.F.: Bronchial responsiveness to histamine or methacholine in asthma: measurement and clinical significance. J. Allergy Clin. Immunol. 68, 347-355 (1981)

4 O'Byrne, P.M., Aizawa, H., Bethel, R.A., Chung, K.F., Nadel, J.A. and Holtzman, M.J.: Prostaglandin $F_{2 z}$ increases responsiveness of pulmonary airways in dogs. Prostaglandins 28, 537-543 (1984)

5 O'Byrne, P.M., Leikauf, G.D., Aizawa, H., Bethel, R.A., Ueki, I.F., Holtzman, M.J. and Nadel, J.A.: Leukotriene B $_{4}$ induces airway hyperresponsiveness in dogs. J. Appl. Physiol. 59, $1941-1946$ (1985)

6 Aizawa, H., Chung, K.F., Leikauf, G.D., Ueki, U., Bethel, R.A., O'Byrne, P.M., Hirose, T. and Nadel, J.A.: Significance of thromboxane generation in ozone-induced airway hyperresponsiveness in dogs. J. Appl. Physiol. 59, 1918- 1923 (1985)

7 Ishida, K., Kelly, L.J., Thomson, R.J., Beattie, L.L. and Schellenberg, R.R.: Repeated antigen challenge induces airway hyperresponsiveness with tissue eosinophilia in guinea pigs. $\mathbf{J}$. Appl. Physiol. 67, 1133-1139 (1989)

8 Boichot, E., Lagente, V., Carre, C., Waltmann, P., MenciaHuerta, J.M. and Braquet, P.: Bronchial hyperresponsiveness and cellular infiltration in the lung of guinea-pigs sensitized and challenged by aerosol. Clin. Exp. Allergy 21, 67-76 (1991)

9 Wanner, A., Abraham, W.M., Douglas, J.S., Drazen, J.M., Richerson, H.B. and Ram, J.S.: NHLBI Workshop Summary. Models of airway hyperresponsiveness. Am. Rev. Respir. Dis. 141, 253-257 (1990)

10 Elwood, W., Lötvall, J.O., Barnes, P.J. and Chung, K.F.: Characterization of allergen-induced bronchial hyperresponsiveness and airway inflammation in activiely sensitized BrownNorway rats. J. Allergy Clin. Immunol. 88, 951-960 (1991)

11 Renzi, P.M., Sapienza, S., Waserman, S., Du, T., Olivenstein, R., Wang, N.S. and Martin, J.G.: Effect of interleukin-2 on the airway responsiveness to antigen in the rat. Am. Rev. Respir. Dis. 146, $163-169$ (1992)

12 Tada, T. and Okumura, K.: Regulation of homocytotropic antibody formation in the rat. I. Feed-back regulation by passively 
administered antibody. J. Immunol. 106, 1002-1011 (1971)

13 Eidelman, D.H., Bellofiore, S. and Martin, J.G.: Late airway responses to antigen challenge in sensitized inbred rats. Am. Rev. Respir. Dis. 137, 1033-1037 (1988)

14 Konzett, H. and Rössler, R.: Versuchsanordnung zu Untersuchungen an der Bronchialmuskulatur. Arch. Exp. Pathol. Pharmacol. 135, 71-76 (1940) (in German)

15 Evans, T.W., Chung, K.F., Rogers, D.F. and Barnes, P.J.: Effect of platelet-activating factor on airway vascular permeability: possible mechanisms. J. Appl. Physiol. 63, 479-484 (1987)

16 Udaka, K., Tatenchi, Y. and Movat, H.: Simple method for quantitation of enhanced vascular permeability. Proc. Soc. Exp. Biol. Med. 133, 1384-1387 (1970)

17 Solway, J. and Leff, A.R.: Sensory neuropeptides and airway function. J. Appl. Physiol. 71, 2077-2087 (1991)

18 Bellofiore, S. and Martin, J.G.: Antigen challenge of sensitized rats increases airway responsiveness to methacholine. J. Appl. Physiol. 65, 1642-1646 (1988)

19 Gundel, R.H., Gerritsen, M.E., Gleich, G.J. and Wegner, C.D.: Repeated antigen inhalation results in a prolonged airway eosinophilia and airway hyperresponsiveness in primates. $\mathbf{J}$. Appl. Physiol. 68, $779-786$ (1990)

20 Kleeberger, S.R., Wagner, E.M., Adams, G.K., III, Dannenberg, A.M., Jr. and Spannhake, E.W.: Effect of repeated antigen exposure on antigen- and mediator-induced bronchospasm in sheep. J. Appl. Physiol. 59, 1866-1873 (1985)

21 O'Byrne, P.M.: Airway inflammation and airway hyperresponsiveness. Chest 90, 575-577 (1986)

22 Chung, K.F.: Role of inflammation in the hyperreactivity of the airways in asthma. Thorax 41, 657-662 (1986)

23 Barnes, P.J.: Neural control of human airways in health and disease. Am. Rev. Respir. Dis. 134, 1289-1314 (1986)

24 Vornanen, M. and Tirri, R.: Cholinergic responses in different sections of rat airways. Acta Physiol. Scand. 113, 177-182 (1981)

25 Szarek, J.L. and Evans, J.N.: Pharmacologic responsiveness of rat parenchymal strips, bronchi, and bronchioles. Exp. Lung Res. 14, 575-585 (1988)

26 Stretton, D., Belvisi, M.G. and Barnes, P.J.: The effect of sensory nerve depletion on cholinergic neurotransmission in guinea pig airways. J. Pharmacol. Exp. Ther. 260, $1073-1080$ (1992)

27 Ishida, K., Pare, P.D., Thomson, R.J. and Schellenberg, R.R.: Increased in vitro responses of tracheal smooth muscle from hyperresponsive guinea pigs. J. Appl. Physiol. 68, 1316-1320 (1990)

28 Tanaka, D.T., Ando, R.E., Larsen, G.L. and Irvin, C.G.:
Cholinergic mechanisms involved with histamine hyperreactivity in immune rabbit airways challenged with ragweed antigen. Am. Rev. Respir. Dis. 144, 70-75 (1991)

29 Goldie, R.G., Spina, D., Henry, P.J., Lulich, K.M. and Paterson, J.W.: In vitro responsiveness of human asthmatic bronchus to carbachol, histamine, $\beta$-adrenoceptor agonists and theophylline. Br. J. Clin. Pharmacol. 22, 669-676 (1986)

30 Cerrina, J., Ladurie, M.L.R., Labat, C., Raffestin, B., Bayol, A. and Brink, C.: Comparison of human bronchial muscle responses to histamine in vivo with histamine and isoproterenol agonists in vitro. Am. Rev. Respir. Dis. 134, 57-61 (1986)

31 Schellenberg, R.R. and Foster, A.: In vitro responses of human asthmatic airway and pulmonary vascular smooth muscle. Int. Arch. Allergy Appl. Immunol. 75, 237-241 (1984)

32 de Jongste, J.C., Mons, H., Bonta, I.L. and Kerrebijn, K.F.: In vitro responses of airways from an asthmatic patient. Eur. J. Respir. Dis. 71, 23-29 (1987)

33 Bai, T.R.: Abnormalities in airway smooth muscle in fatal asthma. Am. Rev. Respir. Dis. 141, $552-557$ (1990)

34 Holtzman, M.J., Fabbri, L.M., O'Byrne, P.M., Gold, B.D., Aizawa, H., Walters, E.H., Alpert, S.E. and Nadel, J.A.: Importance of airway inflammation for hyperresponsiveness induced by ozone. Am. Rev. Respir. Dis. 127, 686-690 (1983)

35 Fabbri, L.M., Aizawa, H., Alpert, S.E., Walters, E.H., O'Byrne, P.M., Gold, B.D., Nadel, J.A. and Holtzman, M.J.: Airway hyperresponsiveness and changes in cell counts in bronchoalveolar lavage after ozone exposure in dogs. Am. Rev. Respir. Dis. 129, 288-291 (1984)

36 Marsh, W.R., Irvin, C.G., Murphy, K.R., Behrens, B.L. and Larsen, G.L.: Increase in airway reactivity to histamine and inflammatory cells in bronchoalveolar lavage after the late asthmatic response in an animal model. Am. Rev. Respir. Dis. 131, $875-879$ (1985)

37 Murlas, C.G. and Roum, J.H.: Sequence of pathologic changes in the airway mucosa of guinea pigs during ozone-induced bronchial hyperreactivity. Am. Rev. Respir. Dis. 131, 314-320 (1985)

38 Seltzer, J., Bigby, B.G., Stulbarg, M., Holtzman, M.J., Nadel, J.A., Ueki, I.F., Leikauf, G.D., Goetzl, E.J. and Boushey, H.A.: $\mathrm{O}_{3}$-Induced change in bronchial reactivity to methacholine and airway inflammation in humans. J. Appl. Physiol. 60, $1321-1326$ (1986)

39 Gibson, P.G., Manning, P.J., O'Byrine, P.M., GirgisGabardo, A., Dolovich, J., Denburg, J.A. and Hargreave, F.E.: Allergen-induced asthmatic responses. Am. Rev. Respir. Dis. 143, $331-335$ (1991) 